\title{
Medikamentetterlevelse og monitorering av antihypertensiv behandling
}

\author{
Manglende medikamentetterlevelse kan være forklaringen på utilfreds- \\ stillende effekt av medisiner og feiltolkes ofte som behandlingsresis- \\ tens. I møte med pasienter med vedvarende høyt blodtrykk til tross for \\ antihypertensiv behandling, er det derfor viktig å finne ut om pasienten \\ faktisk tar sine medisiner. Formålet med denne artikkelen er å gi en \\ oppdatert oversikt over metoder for å avdekke og følge opp medika- \\ mentetterlevelse. Artikkelen er basert på ikke-systematisk litteratursøk \\ i Pubmed og på seniorforfatternes egne kliniske erfaringer.
}

Hypertensjon er en av de viktigste risikofaktorene for kardiovaskulær sykdom. Av den voksne, norske befolkningen er det om lag $40 \%$ som har et blodtrykk $\geq 140 / 90 \mathrm{~mm} \mathrm{Hg}$ eller behandles for forhøyet blodtrykk (1). Hos mange pasienter med hypertensjon oppnås tilfredsstillende behandlingsresultat ved hjelp av livsstilsendringer i kombinasjon med medikamentell behandling (2). Et mindretall av pasientene forblir likevel hypertensive med kontorblodtrykk $>140 / 90 \mathrm{~mm} \mathrm{Hg}$ til tross for behandling med minst tre antihypertensive medikamenter i høyeste anbefalte og/ eller tolererte doser, der minst ett av medikamentene er et diuretikum. Disse defineres som behandlingsresistente ifølge internasjonale retningslinjer (3).

Enkelte av disse pasientene har sekundær hypertensjon og oppnår ikke blodtrykkskontroll før den bakenforliggende årsaken er behandlet, mens resten ofte blir betegnet som terapiresistente til tross for at de ikke alltid er kontrollert for manglende medikamentetterlevelse. Prevalensen av terapiresistent hypertensjon oppgis å være 3-30\% (4), avhengig av populasjon og definisjon, mens den ekte prevalensen, der pasienter med manglende medikamentetterlevelse er ekskludert, foreløpig er ukjent. Den store variasjonen i oppgitt prevalens skyldes i stor grad mangel på store, prospektive studier med mål om å avdekke prevalensen av terapiresistent hypertensjon og hvor det samtidig er gjennomført målrettet og forhåndsbestemt opptitrering av antihypertensiver (5).

Manglende medikamentetterlevelse er et kjent problem $(6,7)$. I Oslo-RDN (renal denervering)-studien og i studier der terapeutisk medikamentmonitorering er benyttet, blir en betydelig andel av studiepasientene klassifisert som ikke-adherente, altså med delvis eller fullstendig manglende etterlevelse av medikamentell behandling $(8-10)$. Disse resultatene understreker behovet for enkle metoder for å avdekke dårlig medikamentetterlevelse og videre kontroll av denne.

\section{Metoder for monitorering av medikamentetterlevelse}

En rekke ulike metoder er tilgjengelige for å monitorere medikamentetterlevelse (tab 1). Disse kan deles inn i direkte og indirekte metoder som igjen kan deles inn i ulike undergrupper $(11,12)$.

\section{Indirekte metoder}

Selvrapportering. Det finnes flere forskjellige spørreskjemaer for rapportering av medikamentetterlevelse (13). Den mest brukte er Medication Adherence Questionnaire (MAQ). Andre former for selvrapportering er føring av medikamentdagbok og pasientintervju.

Pilletelling. Foruten pasientintervju har manuell pilletelling vært den mest brukte metoden for å kvantifisere etterlevelse (11). Dette er en enkel metode hvor pasienten tar med ubrukte doser til konsultasjon for registrering.

Elektronisk dosett er en metode som har vært på markedet siden 1988 og går ut på automatisk registrering av tidspunkt for uttak av medisin (12). Området er i kontinuerlig utvikling, og den siste nyvinningen er en videreutviklet utgave av dosetten hvor elektronisk registrering først finner sted etter at medikamentet er svelget. Pasienten svelger en sensor sammen med medisinene, og inntaket registreres av et belte pasienten har rundt livet. Registreringen kan således synkroniseres med en mobiltelefonapplikasjon for å lette monitoreringen (14). Teknologien ble i utgangspunktet utviklet som et alternativ til direkte observert medikamentinntak i behandling av tuberkulose (15). Apper er også utviklet uavhengig av den beskrevne metoden. Disse tillater registrering av inntatte doser i kombinasjon med

\author{
Per Anders Eskås \\ Sondre Heimark \\ Julian Eek Mariampillai \\ Medisinsk fakultet \\ Universitetet i Oslo
}

Anne Cecilie K. Larstorp

Avdeling for medisinsk biokjem Klinikk for laboratoriemedisin og

Enhet for indremedisinsk forskning Oslo universitetssykehus, Ullevål

Fadl Elmula Mohamed Fadl Elmula Avdeling for hjertemedisin og avdeling for generell indremedisin

Medisinsk klinikk

Oslo universitetssykehus, Ullevål

og

Institutt for klinisk medisin,

Medisinsk fakultet

Universitetet i Oslo

\section{Aud Høieggen}

aud.hoieggen@medisin.uio.no

Nyremedisinsk avdeling

Medisinsk klinikk

Oslo universitetssykehus, Ullevål

og

Institutt for klinisk medisin

Medisinsk fakultet

Universitetet i Oslo

\section{HOVEDBUDSKAP}

Manglende medikamentetterlevelse er en av hovedårsakene til at pasienter med hypertensjon ikke når behandlingsmål, og dette omfatter rundt halvparten av pasienter med angivelig terapiresistent hypertensjon

Dårlig medikamentetterlevelse kan blant annet avdekkes med terapeutisk medikamentmonitorering eller direkte observert medikamentinntak med påfølgende 24 timers ambulatorisk blodtrykksmåling

Terapeutisk medikamentmonitorering kan i tillegg gi oss økt kunnskap om forskjeller i pasienters metabolisme av medikamenter 
nyttig påminnelsesfunksjon, og er utviklet for at lege og pasient lettere kan monitorere medikamentinntaket.

En annen form for pilletelling er overvåking av resepter, enten ved registrering av reseptfornyelsesfrekvens eller uthentede resepter. Disse metodene gir mulighet for å overvåke når og hvor ofte pasienter fornyer eller henter ut medisiner som et mål på etterlevelse.

\section{Direkte metoder}

Bevitnet inntak. For å sikre inntak av medisinen før man måler effekten av denne, benyttes direkte observert medikamentinntak. Denne metoden består $i$ at undersøker ser at pasienten tar forskrevne medisiner i korrekte doser fra original medikamentemballasje før eventuelle undersøkelser gjennomføres, eksempelvis blodtrykksmåling. Ofte overvåkes pasientene en stund i ettertid for å utelukke oppkast eller utspytting av medisin.

Terapeutisk medikamentmonitorering $i$ blod eller urin. Terapeutisk medikamentmonitorering omfatter funn og kvantifisering av antihypertensive medikamenter eller lettere detekterbare metabolitter. Analysene kan gjøres i blod eller urin. I Norge brukes teknologien i rettsmedisinsk sammenheng for antihypertensive medikamenter, men i vanlig klinisk praksis er analysene foreløpig lite tilgjengelige. På nåværende tidspunkt finnes det kun analyser for noen få klasser av antihypertensiver i Norge.

\section{Diskusjon}

Det er en stor utfordring for alle som behandler pasienter med hypertensjon at så mange ikke oppnår anbefalt behandlingsmål (4). Vi vet $i$ dag at en relativt stor andel av disse pasientene ikke tar forskrevne medisiner, noe som allerede i 1988 ble understreket i litteraturen (7). Manglende etterlevelse og påfølgende feilaktig diagnostisering kan medføre store sosiale og økonomiske konsekvenser for pasienten og samfunnet for øvrig. Mange vil gjennomgå unødvendig utredning, noe som krever ressurser som kunne vært brukt til andre pasienter og formål. På nåværende tidspunkt finnes det ingen gullstandard for å oppdage pasienter med manglende medikamentetterlevelse. I bruken av de tidligere omtalte metodene er derfor bevissthet rundt metodenes styrker og svakheter sentralt.

En svakhet ved mange av metodene er pasientens mulighet for manipulering av resultatet (12), og det er et kjent problem at pasienter tenderer mot å overestimere eget medikamentforbruk ved selvrapportering (16). Likevel er noen av metodene billige å gjennomføre og egner seg av den grunn $i$ langtidsoppfølging av pasienter. Øvrige styrker og svakheter er beskrevet $i$ tabell 2 .

Direkte observert medikamentinntak er

Tabell 1 Oversikt over tilgjengelige metoder for medikamentmonitorering

\begin{tabular}{|c|c|c|c|}
\hline \multicolumn{2}{|c|}{ Indirekte metoder } & \multicolumn{2}{|c|}{ Direkte metoder } \\
\hline Selvrapportering & Pilletelling & Bevitnet inntak & $\begin{array}{l}\text { Terapeutisk } \\
\text { medikamentmonitorering }\end{array}$ \\
\hline $\begin{array}{l}\text { Spørreskjema } \\
\text { Dagbok } \\
\text { Intervju }\end{array}$ & $\begin{array}{l}\text { Manuelt } \\
\text { Elektronisk dosett } \\
\text { Reseptregisterbasert }\end{array}$ & $\begin{array}{l}\text { Direkte observert } \\
\text { medikamentinntak }\end{array}$ & $\begin{array}{l}\text { Analyse av blod } \\
\text { Analyse av urin }\end{array}$ \\
\hline
\end{tabular}

den eneste metoden som sikrer at riktig medikament tas til rett tid og i rett dose. I kombinasjon med påfølgende 24-timers ambulatorisk blodtrykksmåling er den velegnet til å oppdage dårlig etterlevelse av antihypertensiv medikasjon. Metoden ble i utgangspunktet utviklet for å sikre inntak av medisiner hos pasienter med tuberkulose (17) og brukes i dag også regelmessig i behandling av pasienter med psykiatriske lidelser, ofte som ledd i tvungent psykisk helsevern uten døgnopphold. Vår erfaring fra Oslo-RDN-studien er at direkte observert medikamentinntak kan ha en viktig plass i utredningen av terapiresistent hypertensjon, da man i stor grad evner å fange opp manglende etterlevelse som ikke tidligere er erkjent $(8,9$, 18). Så snart man kan dokumentere at medisinen faktisk virker hvis den blir tatt i rett dose, har man et bedre grunnlag for å diskutere behandlingen med pasienten. Selv om medikamentene ikke forventes å nå maksimal serumkonsentrasjon etter kun én dose hos pasienter som ellers ikke tar medisiner, er vår erfaring at vi likevel kan oppdage manglende etterlevelse hos så mye som $30 \%$ av pasienter med behandlingsresistent hypertensjon (19). Det egentlige tallet ligger sannsynligvis noe høyere.

Ved terapeutisk medikamentmonitorering måles virkestoff eller spesifikke metabolitter i blod eller urin. Dermed kan man avdekke om pasienten faktisk har tatt medisinen og om dosen er adekvat. I noen tilfeller vil ikke faktisk inntatt medikament $i$ antatt optimal dose gi adekvat serumkonsentrasjon. Metoden vil således kunne bidra til å avdekke endret metabolisme av medikamenter, eksempelvis grunnet CYP-polymorfismer. Svekket medisineffekt vil føre til terapisvikt, mens forsterket medisineffekt kan føre til økte bivirkninger. Ved å kombinere både terapeutisk medikamentmonitorering og undersøkelse av CYP-polymorfismer kan man individualisere og dermed optimalisere blodtrykksbehandlingen.

I flere studier har man brukt terapeutisk medikamentmonitorering for å evaluere medikamentetterlevelse, og ikke-målbare eller for lave medikamentkonsentrasjoner i forhold til referanseverdi i blodet påvises hos en betydelig andel pasienter. Fenomenet beskrives godt av Brinker og medarbeidere der pasientene i utgangspunktet var uvitende om at det ble utført monitorering av antihypertensiver i blod, og initialt benektet alle pasientene manglende etterlevelse (10). Etter at pasientene ble konfrontert med resultatene og årsaker til manglende medikamentetterlevelse ble identifisert og fulgt opp, falt blodtrykket med $46 \pm 10 / 26 \pm 14$ $\mathrm{mm} \mathrm{Hg}$ i gruppen hvor medikamentetterlevelsen var betegnet som dårlig, uten at antall medikamenter eller dosen ble endret. I gruppen hvor medikamentetterlevelsen var betegnet som god, var tilsvarende blodtrykksfall $12 \pm 17 / 7 \pm 7 \mathrm{~mm} \mathrm{Hg}$.

En svakhet ved alle former for intermitterende testing, inkludert direkte observert medikamentinntak og terapeutisk medikamentmonitorering, er at pasienter ofte bedrer sin etterlevelse rett i for- og etterkant av konsultasjonen med en eventuell måling. Fenomenet er kjent som «white-coat adherence» (12), og gir inntrykk av at pasientens medikamentetterlevelse er bedre enn hva den faktisk er. Uansett vil man kunne oppdage at pasientens blodtrykk lar seg behandle med forskrevne medisiner, og en slik måling vil dermed kunne bli en viktig del av utredningen av tilsynelatende terapiresistent hypertensjon.

Det er også etiske betenkeligheter ved bruk av terapeutisk medikamentmonitorering $i$ antihypertensiv behandling som må tas hensyn til. Pasientenes autonomi må respekteres og de bestemmer selvsagt selv om medikamentell behandling er noe de vil takke ja til. I studiesammenheng har man eksempelvis benyttet terapeutisk medikamentmonitorering uten at pasientene har vært klar over dette. En slik fremgangsmåte vil ikke være forenlig med god legegjerning i klinisk praksis. Utover bruk av terapeutisk medikamentmonitorering er det flere etiske momenter som gjør seg gjeldende $\mathrm{i}$ behandling av kroniske tilstander og ved vurdering av manglende etterlevelse. Vi mener at behandleren må være bevisst sin plikt til å utforske årsaker og diskutere tiltak som kan bidra til å bedre etterlevelsen og på den måten føre til bedre blodtrykkskontroll. Et godt lege-pasient-forhold 
Tabell 2 Oversikt over fordeler og ulemper ved de ulike metodene for medikamentmonitorering

Metode $\quad$ Fordeler Ulemper

\section{Selvrapportering}

$\begin{array}{ll}\text { Spørreskjema } & \text { Enkel å benytte } \\ & \text { Billig } \\ & \text { Avdekker årsaker til manglende medikament- } \\ & \text { etterlevelse } \\ \text { Dagbok } & \text { Enkel å benytte } \\ & \text { Billig } \\ \text { Intervju } & \text { Enkel å benytte } \\ & \text { Billig }\end{array}$

Pasienter kan lett manipulere resultatet og overestimere eget medikamentforbruk

\section{Pilletelling}

Manuelt

\section{Elektronisk dosett}

Reseptregistre

Bevitnet inntak

Direkte observert medikamentinntak

Enkel å benytte

Sikrer at medikamentet faktisk er inntatt
Enkel å benytte Billig

\section{Enkel å benytte}

Mulighet for monitorering av tidspunkt for inntak hvis man antar at åpnet boks tilsvarer inntak av medisin

\section{Enkel å benytte} Billig

\section{Pasientmanipulering; overestimerer eget} medikamentforbruk

Pasientmanipulering; overestimerer eget medikamentforbruk
Pasientmanipulering; pasienten tar ikke med/ skjuler ikke-inntatte medikamenter

Pasientmanipulering; åpning av dosett er nok for registrering av inntak, men sikrer ikke at pasienten faktisk tar medisinen

Pasientmanipulering; sikrer ikke inntak
Ressurskrevende hvis det skal gjennomføres hyppig og overvåkes tilfredsstillende etter medikamentinntak

Mulighet for underestimering av effekt ved inntak av én dose medikament

\section{Terapeutisk medikamentmonitorering}

Analyse i blod eller urin
Sikrer at medikamentet faktisk er inntatt Kan avdekke endret metabolisme av medikamenter
Ressurskrevende ved hyppige målinger. Avdekker ikke bedret etterlevelse rundt målingstidspunkt

Ukjent tidspunkt for inntak og dose av medikament vil være grunnlaget for å komme i mål med slike diskusjoner.

Når det gjelder bruk av direkte observert medikamentinntak, benyttes dette jevnlig i eksempelvis psykisk helsevern, behandling av allmennfarlige, smittsomme sykdommer som tuberkulose og i rusomsorgen. Likevel kan man ikke på noen måte forsvare tvungen innføring av direkte observert medikamentinntak i behandling av hypertensjon, da dette er en tilstand av svært annen karakter enn nevnte eksempler. Man kan også spørre seg om hvor lenge man skal tilby samtykkekompetente pasienter behandling, når de på tross av grundig informasjon om tilstanden og dens konsekvenser likevel velger ikke å ta sine medisiner.

\section{Konklusjon}

I en klinisk hverdag vil direkte observert medikamentinntak etterfulgt av 24-timers ambulatorisk blodtrykksmåling være den best egnede måten til å avdekke manglende etterlevelse. Metoden vil være egnet til alle som behandler pasienter med hypertensjon, fra allmennpraktikere til spesialister i indremedisin. Det må presiseres at metoden kun egner seg i utredningen av manglende etterlevelse og ikke skal inngå i den daglige antihypertensive behandlingen. Vi ser for oss at for pasienter der oppfølging av manglende etterlevelse er aktuelt, vil det kunne være mulig med årlige kontroller med direkte observert medikamentinntak og ambulatorisk blodtrykksmåling. På den måten vil man igjen kunne øke pasientens bevissthet rundt viktigheten av behandlingen og få en anledning til å diskutere utfordringer som er med på å redusere etterlevelsen. En hyppigere oppfølging vil kunne basere seg på terapeutisk medikamentmonitorering, måling av medikamentkonsentrasjon i blod eller urin. Da metoden etter vår mening vil være et nyttig hjelpemiddel i antihypertensiv behandling, håper vi den også vil bli lettere tilgjengelig i Norge i overskuelig fremtid.

\section{Per Anders Eskås (f. 1991)}

er medisinstudent ved Universitet i Oslo. Forfatter har fylt ut ICMJE-skjemaet og oppgir ingen interessekonflikter.

\section{Sondre Heimark (f. 1989)}

er medisinstudent ved Universitet i Oslo. Forfatter har fylt ut ICMJE-skjemaet og oppgir ingen interessekonflikter.

\section{Julian Eek Mariampillai (f. 1992)}

er medisinstudent ved Universitetet i Oslo. Forfatter har fylt ut ICMJE-skjemaet og oppgir ingen interessekonflikter. 


\section{Anne Cecilie K. Larstorp (f. 1980)}

er ph.d., lege i spesialisering i medisinsk biokjemi og forsker på temaet hypertensjon.

Forfatter har fylt ut ICMJE-skjemaet og oppgir følgende interessekonflikter: Hun har mottatt personlig honorar fra MSD og Hemo Sapiens.

Fadl Elmula Mohamed Fadl Elmula (f. 1972) er spesialist $\mathrm{i}$ indremedisin og i hjertesykdommer og er stipendiat og universitetslektor. Forfatter har fylt ut ICMJE-skjemaet og oppgir følgende interessekonflikter: Han har mottatt personlig honorar fra Medtronic, Hemo Sapiens og Amgen.

\section{Aud Høieggen (f. 1956)}

er dr.med., spesialist i indremedisin og i nyresykdommer, overlege og førsteamanuensis. Forfatter har fylt ut ICMJE-skjemaet og oppgir følgende interessekonflikter: Hun har mottatt personlig honorar fra MSD og Amgen.

\section{Litteratur}

1. Klouman M, Asberg A, Widerøe TE. Blodtrykksnivå i en norsk befolkning - betydningen av arv og livsstil. Tidsskr Nor Legeforen 2011; 131: 1185-9.

2. Mancia G. Fagard R, Narkiewicz K et al. 2013 ESH/ ESC Guidelines for the management of arterial hypertension: the Task Force for the management of arterial hypertension of the European Society of Hypertension (ESH) and of the European Society of Cardiology (ESC). J Hypertens 2013; 31: 1281-357.

3. Calhoun DA, Jones D, Textor $S$ et al. Resistant hypertension: diagnosis, evaluation, and treatment. A scientific statement from the American Heart Association Professional Education Committee of the Council for High Blood Pressure Research. Hypertension 2008; 51: 1403-19.

4. Persu A, Jin Y, Baelen M et al. Eligibility for renal denervation: experience at 11 European expert centers. Hypertension 2014; 63: 1319-25.

5. Fagard RH. Resistant hypertension. Heart 2012; 98: 254-61.

6. The 1988 report of the Joint National Committee on Detection, Evaluation, and Treatment of High Blood Pressure. Arch Intern Med 1988; 148: 1023-38.

7. Klein LE. Compliance and blood pressure control. Hypertension 1988; 11: $1161-4$

8. Fadl Elmula FE, Hoffmann P, Larstorp AC et al. Adjusted drug treatment is superior to renal sympathetic denervation in patients with true treatment-resistant hypertension. Hypertension 2014; 63: $991-9$.

9. Fadl Elmula FE, Hoffmann P. Fossum E et al. Renal sympathetic denervation in patients with treatment-resistant hypertension after witnessed intake of medication before qualifying ambulatory blood pressure. Hypertension 2013; 62: 526-32.

10. Brinker S, Pandey A, Ayers $C$ et al. Therapeutic drug monitoring facilitates blood pressure control in resistant hypertension. J Am Coll Cardiol 2014: 63: $834-5$.

11. Osterberg L, Blaschke T. Adherence to medication. N Engl J Med 2005; 353: 487-97.

12. Burnier M, Wuerzner G, Struijker-Boudier $\mathrm{H}$ et al. Measuring, analyzing, and managing drug adherence in resistant hypertension. Hypertension 2013; 62: $218-25$
13. Culig J, Leppée M. From Morisky to Hill-bone; self-reports scales for measuring adherence to medication. Coll Antropol 2014; 38: 55-62.

14. Dicarlo L, Naik R, Macey N. An ingestible sensor and wearable patch tracking adherence and activity patterns identified underlying factors leading of persistent hypertension: a real-world registry study. London: European Society of Cardiology Congress, 2015

15. Belknap R, Weis S, Brookens A et al. Feasibility of an ingestible sensor-based system for monitoring adherence to tuberculosis therapy. PLoS One 2013; 8: e53373.

16. Garfield S, Clifford S, Eliasson L et al. Suitability of measures of self-reported medication adherence for routine clinical use: a systematic review. BMC Med Res Methodol 2011: 11: 149

17. Wejse C. Tuberculosis elimination in the post Millennium Development Goals era. Int J Infect Dis 2015; 32: 152-5.

18. Sørensen H, Fadl Elmula FE, Kjeldsen SE et al. Renal sympatisk denervering ved terapiresistent hypertensjon. Tidsskr Nor Legeforen 2014; 134: 32-6.

19. Eskås PA, Heimark S, Fadl Elmula FE et al. Nonadherence revealed by witnessed intake of antihypertensive drugs prior to ambulatory blood pressure monitoring was the main reason for noneligibility in the Oslo RDN study. J Hypertens 2015 33: PP.26.28.

Mottatt 15.9. 2015, første revisjon innsendt 22.1. 2016, godkjent 18.3. 2016. Redaktør: Liv-Ellen Vangsnes.

ANNONSE 